\title{
FOXI1 Immunohistochemistry Differentiates Benign Renal Oncocytoma from Malignant Chromophobe Renal Cell Carcinoma
}

\author{
AGNES MOLNAR ${ }^{1}$, CSENGE ANNA HORVATH $^{1}$, PETRA CZOVEK ${ }^{1}$, ARPAD SZANTO ${ }^{1}$ and GYULA KOVACS ${ }^{1,2}$ \\ ${ }^{1}$ Department of Urology, Medical School, University of Pecs, Pecs, Hungary; \\ ${ }^{2}$ Medical Faculty, Ruprecht Karls University, Heidelberg, Germany
}

\begin{abstract}
Background/Aim: Renal oncocytoma (RO) and chromophobe renal cell carcinoma (chRCC) are suggested to develop from $\alpha$ - and $\beta$-intercalated (IC) cells of the collecting duct expressing solute carrier family 4 member 1 (SLC4A1) and SLC26A4 under control of forkhead box 1 (FOXI1) transcription factor. The aim of this study was to clarify the possible cellular origin and of RO and chRCC. Materials and Methods: Immunohistochemistry for aquaporin 2 (AQP2), FOXI1, SLC4A1 and SLC16A4 was applied to distinct types of renal cell tumors. Results: Nuclear FOXI1 staining occurred in $96 \%$ of 83 ROs, in $3 \%$ of 90 chRCCs and none of the other tumor types. The $\alpha-I C$ cell marker SLC4A1 was seen in $60 \%$ of RO and $11 \%$ of chRCC, whereas staining for the $\beta$-IC cell marker SLC26A4 was negative in all but one tumor. Conclusion: Although the origin of RO remains unclear, our findings suggest that FOXI1 immunohistochemistry is useful in differential diagnosis of RO from chRCC with overlapping histology.
\end{abstract}

Renal oncocytoma (RO) and chromophobe renal cell carcinoma (chRCC) each account for approximately 5-8\% of surgically removed renal tumors. In spite of growth into small veins or 'infiltration' of the parenchyma or perirenal fat tissue, RO is considered to be a benign tumor (1). Although chRCC has a good prognosis, it is a malignant tumor with a tendency for sarcomatous transformation and metastatic growth in around 5-10\% of cases (2). Taking into account the biology of the two types of neoplasms, the

Correspondence to: Gyula Kovacs, Department of Urology, Medical School, University of Pecs, Munkacsy M. u. 2, H-7621 Pecs, Hungary. Tel: +36 72507334, Fax: +36 72242374, e-mail: g.kovacs@gmx.de, gyula.kovacs@urz.uni-heidelberg.de ORCID: 0000-0003-2890-3781

Key Words: Renal oncocytoma, chromophobe renal cell carcinoma, FOXI1, immunohistochemistry, differential diagnosis. differential diagnosis is of clinical importance. The diagnosis of typical RO and chRCC based on their morphology can be achieved by routine histology in the vast majority of cases. However, morphological variants of $\mathrm{RO}$, oncocytic variants of chRCC or 'hybrid' RO and chRCC may give rise to problem $\mathrm{s}$ in differential diagnosis $(3,4)$.

It was proposed 30 years ago that RO and chRCC develop from intercalated (IC) cells of the collecting duct (CD) (5, $6)$. As nine out of 10 ROs were found to express $\alpha$-IC cell marker solute carrier family 4 member 1 (SLC4A1), it was suggested that RO develops from $\alpha$-IC cells. Recently, a meta-analysis of gene-expression data described overexpression of forkhead box 1 (FOXII) and SCL4AI in chRCC, and the authors suggested the $\alpha$-IC cells to be the source of chRCC (7). However, by applying whole-genome sequencing analysis or Affymetrix GeneChip analysis, no tumor-specific overexpression of FOXII and SCL4AI was found in two series of $\operatorname{chRCC}(8,9)$.

The connecting tubules (CTs) and CDs contain four distinct cell types: Principal cells (PCs), $\alpha$-IC cells, $\beta$-IC cells and non- $\alpha$-non- $\beta$-IC cells. PCs express aquaporin 2 (AQP2); basolateral expression of the SLC4A1 characterizes $\alpha$-IC cells, whereas apical expression of the solute carrier family 16 member 4 (SLC16A4) is characteristic of $\beta$-IC cells (10). The expression of SLC4A1 and SLC26A4 during differentiation into $\alpha$ - and $\beta$-IC cells is controlled by FOXI1 transcription factor (11). Non- $\alpha$-non- $\beta$-IC cells express both SLC26A4 and ATPase $\mathrm{H}^{+}$transporting V1 subunit B1 (ATP6V1B1) (12).

Although RO and chRCC can be unequivocally differentiated by genetic means (13-15), in routine laboratory practice, immunohistochemistry is the choice of technique $(16,17)$. To date, among several other tested genes only cytokeratin 7 (KRT7) and CD82 were found to be a useful marker for $\operatorname{chRCC}(18,19)$. In an attempt to clarify the possible cellular origin of and find a diagnostic marker for RO and chRCC, we applied AQP2, FOXI, SLC4A1 and SLC26A4 immunohistochemistry to a large 
number of distinct types of renal cell tumors placed on tissue microarray (TMA).

\section{Materials and Methods}

Tissue samples. Tumor samples were collected from patients who had undergone radical or partial nephrectomy for RCC between 2000 and 2014 at the Department of Urology, Medical School, University of Pecs, Hungary. The histological diagnosis was reviewed by a pathologist (GK) according to the Heidelberg classification system (20). We included several ROs with cellular and growth variation and chRCCs with classic, eosinophil and mixed morphology. NoBirt-Hogg-Dube syndrome-associated 'hybrid' tumor was analyzed in this study. Three out of the 83 ROs displayed 'pseudo-invasion' into the perirenal fat tissue. We included two cases of multiplex ROs and also an RO developed in end-stage renal disease. Seven out of 90 chRCCs displayed an aggressive growth pattern, sarcomatous changes and metastatic growth. All grades, TNM groups and stages were present among the 220 conventional RCCs, including cases with 'eosinophilic' or 'oncocytic' phenotype. Tumors of $5 \mathrm{~mm}$ to $8 \mathrm{~cm}$ were also included in the panel of 121 papillary RCC. Normal adult kidneys obtained from nephrectomy were used to localize the expression of genes in the nephron. The collection and use of all tissue samples for this study was approved by the Ethics Committee of the University of Pecs (5343/2014).

TMA and immunohistochemistry. Hematoxylin and eosin-stained slides were reviewed to select representative paraffin blocks for TMA construction. From each tumor, a minimum of three core biopsies with a diameter of $0.6 \mathrm{~mm}$ were placed in the recipient block using a Manual Tissue Arrayer (MTA1; Beecher Instruments, Inc., Sun Prairie, WI, USA). For marking the TMAs, fetal and adult kidney biopsies were included. After dewaxing and rehydration, the $4 \mu \mathrm{m}$-thick sections were subjected to heat-induced epitope retrieval in $10 \mathrm{mM}$ sodium citrate buffer $(\mathrm{pH} \mathrm{6.0)}$ ) or TE buffer $(\mathrm{pH} \mathrm{9.0)} \mathrm{in}$ 2100-Retriever (Pick-Cell Laboratories, Amsterdam, the Netherlands). Endogenous peroxidase activity and nonspecific binding sites were blocked with $3 \%$ hydrogen peroxide containing $1 \%$ normal horse serum for 15 minutes at room temperature. Slides were incubated overnight at $4{ }^{\circ} \mathrm{C}$ in a moist chamber with rabbit polyclonal anti-AQP2 (PA5-38004; Thermo Fisher, Budapest, Hungary) at a dilution of 1:500, rabbit polyclonal anti-FOXI1 (PA530031; Thermo Fisher) at a dilution of 1:200, rabbit polyclonal antiSLC4A1 (HPA015584; Sigma-Aldrich, Budapest, Hungary) at a dilution of 1:200, and mouse polyclonal anti-SLC26A4 (Abnova, Taipei, Taiwan, ROC) at a dilution of 1:100. Horse-radishperoxydase-conjugated anti-rabbit, anti-mouse secondary antibody (HISTOLSMR, Histopathology Ltd, Pecs, Hungary) was applied for 30 minutes at room temperature and color was developed using aminoethyl carbazole (AEC) or 3,3'diamonobenzidine (DAB) substrate (Dako, Glostrup, Denmark). Tissue sections were counterstained with Mayer's haematoxylin (Lillie's modification; Dako) and after bluing for 10 seconds were mounted using Glycergel Mounting Medium (Dako) or PERTEX (medite Ltd. Burgdorf, Germany). For negative controls, the primary antibody was omitted. In each positive case, at least $80 \%$ of tumor cells showed a weak to strong nuclear staining for FOXI1 as estimated under microscopy.
Table I. Expression of connecting and collecting duct markers in renal cell tumors.

\begin{tabular}{lrrrrr}
\hline Tumor & $\begin{array}{c}\text { No. of } \\
\text { tumors }\end{array}$ & FOXI1+ & SLC4A1+ & SLC26A4+ & AQP2+ \\
\hline RO & 83 & $96 \%$ & $60 \%$ & $0 \%$ & $0 \%$ \\
chRCC & 90 & $3 \%$ & $11 \%$ & $1 \%$ & $0 \%$ \\
cRCC & 220 & $0 \%$ & $0 \%$ & $0 \%$ & $0 \%$ \\
pRCT & 121 & $0 \%$ & $0 \%$ & $0 \%$ & $0 \%$ \\
\hline
\end{tabular}

FOXI1: Forkhead box 1; SLC4A1: solute carrier family 4 member 1; SLC26A4: solute carrier family 26 member 4; AQP2: aquaporin 2; RO: renal oncocytoma; chRCC: chromophobe renal cell carcinoma; cRCC: conventional renal cell carcinoma; pRCT: papillary renal cell tumor.

\section{Results}

Expression of AQP2, FOXI1, SLC4A1 and SLC26A4 in normal kidney. We found strong AQP2 staining at the luminal surface of cortical and medullary CD cells. FOXI1 was expressed in cells of CT and cortical CD cells (Figure 1A). To study the FOXI1 downstream target proteins, we looked for the expression of SLC4A1 and SCL26A4 in normal kidney. In normal adult kidney, SLC4A1 was expressed basolaterally in $15-50 \%$ of the CT cells, less frequently in the cortical $\mathrm{CD}$ cells, while in the medullary CDs, only single cells were positive (Figure 2A). The antibody to SLC26A4 revealed apical expression in a few CT cells (Figure 2E).

Expression of AQP2, FOXI1, SLC4A1 and SLC26A4 in renal cell tumours. We evaluated AQP2, FOXI1, SLC4A1 and SLC26A4 expression on TMAs containing core biopsies of 83 ROs, 90 chRCCs, 220 conventional RCCs and 121 papillary RCCs, as well as cortical and medullary biopsies of normal adult kidneys. The latter served as internal control for immunoreaction in the TMAs. The results are summarized in Table I. None of the conventional and papillary RCCs, ROs or chRCCs displayed positive reaction with the AQP2 antibody.

Applying FOXI1 immunohistochemistry, we detected nuclear FOXI1 staining in 80 (96\%) out of $83 \mathrm{RO}$, (Figure $1 \mathrm{~B}$ and $\mathrm{C}$ ). As weak to strong nuclear staining was seen in 80-100\% of RO cells as shown in Figure 1B and C, we considered these results as a positive reaction. One of the FOXI1-negative ROs was obtained from an end-stage renal disease kidney and was also negative for SLC4A1. The two other FOXI1-negative ROs displayed densely packed small eosinophilic cells arranged in solid-nested architecture. The vast majority of chRCCs were negative for FOXI1 staining (Figure 1D) and only three (3\%) out of 90 chRCCs showed a positive reaction. One of the three FOXI1-positive chRCCs showed weakly positive staining in only one of the three core 

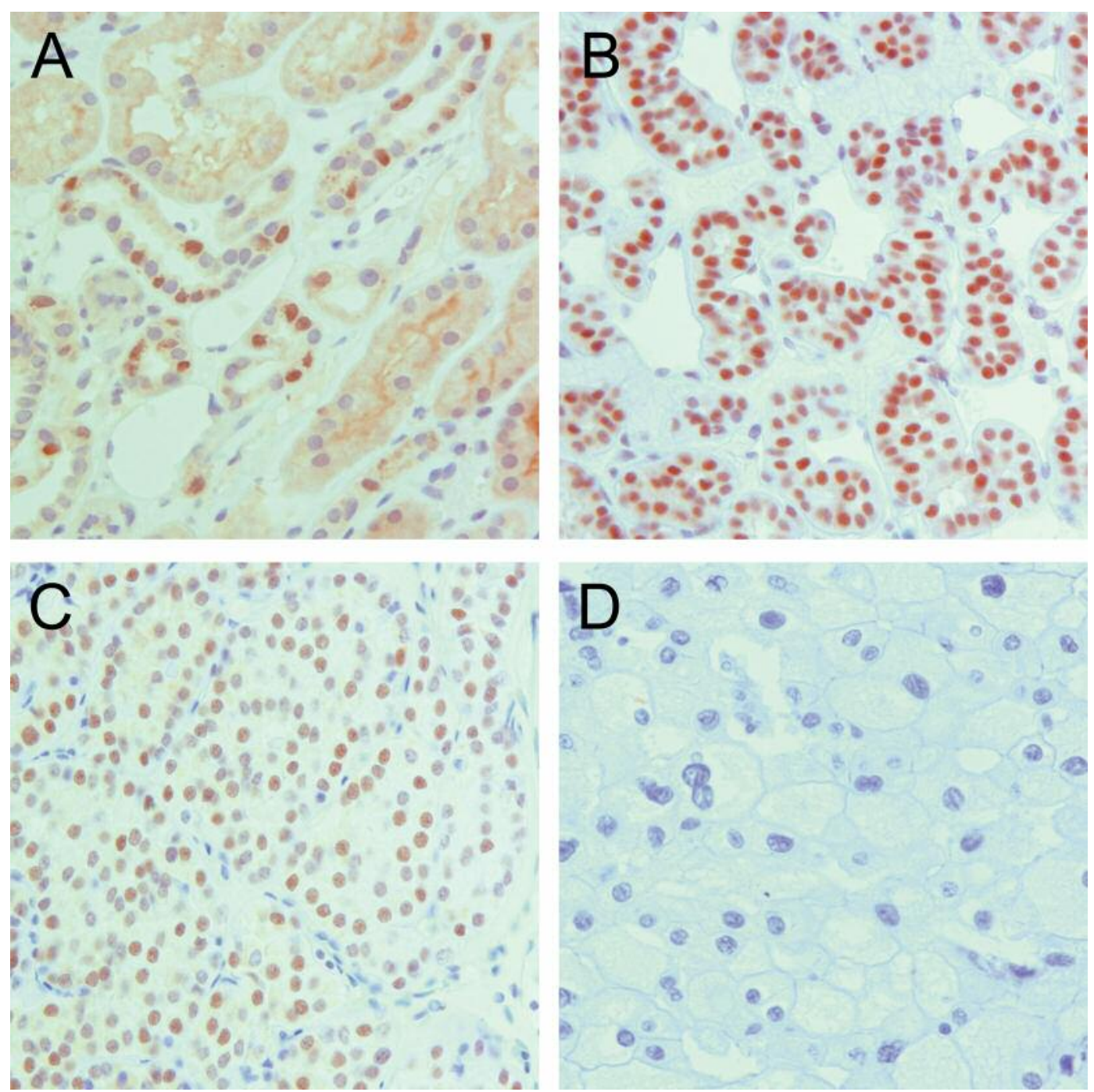

Figure 1. Expression of forkhead box 1 (FOXI1) in connecting tubules of normal kidney and tumor tissues. A: FOXI1 expression in nuclei of cells of the cortical connecting duct. B and C: Nuclear staining of FOXI1 in renal oncocytoma. D: Lack of FOXI1 staining in chromophobe renal cell carcinoma. Scale bar: $25 \mu \mathrm{m}$.

biopsies. This tumor showed classic chromophobe histology and had given rise to a liver metastasis. The diagnosis of chRCC was also confirmed by DNA array analysis which showed the loss of specific chromosomes (data not shown). The additional two cases with weak FOXI1 positivity displayed histology of classical chRCC. None of the 220 conventional or 121 papillary RCCs showed positive staining with the FOXI1 antibody.

Immunohistochemistry with the $\alpha$-IC marker SLC4A1 showed positive staining with variable intensity in $50(60 \%)$ out of the 83 ROs (Figure 2B and C). The localization of SLC4A1 in ROs was very similar to that of normal CT cells. The number of positive cells varied between $50-90 \%$. Only
$10(11 \%)$ out of the 90 chRCCs showed positive staining with SLC4A1 antibody but in these cases, nearly $100 \%$ of the cells displayed discrete, weak membranous staining (Figure 2D). None of the conventional RCCs and papillary RCCs showed a positive reaction with the SLC4A1 antibody. Staining for the $\beta$-IC cell marker SLC26A4 was positive in only one chRCC (Figure 2F), but not in any other tumor.

\section{Discussion}

We found positive nuclear FOXI1 staining in $96 \%$ of ROs and only $3 \%$ of chRCCs and none of other types of renal cell tumor, including 'oncocytic' cellular variants. Positive 

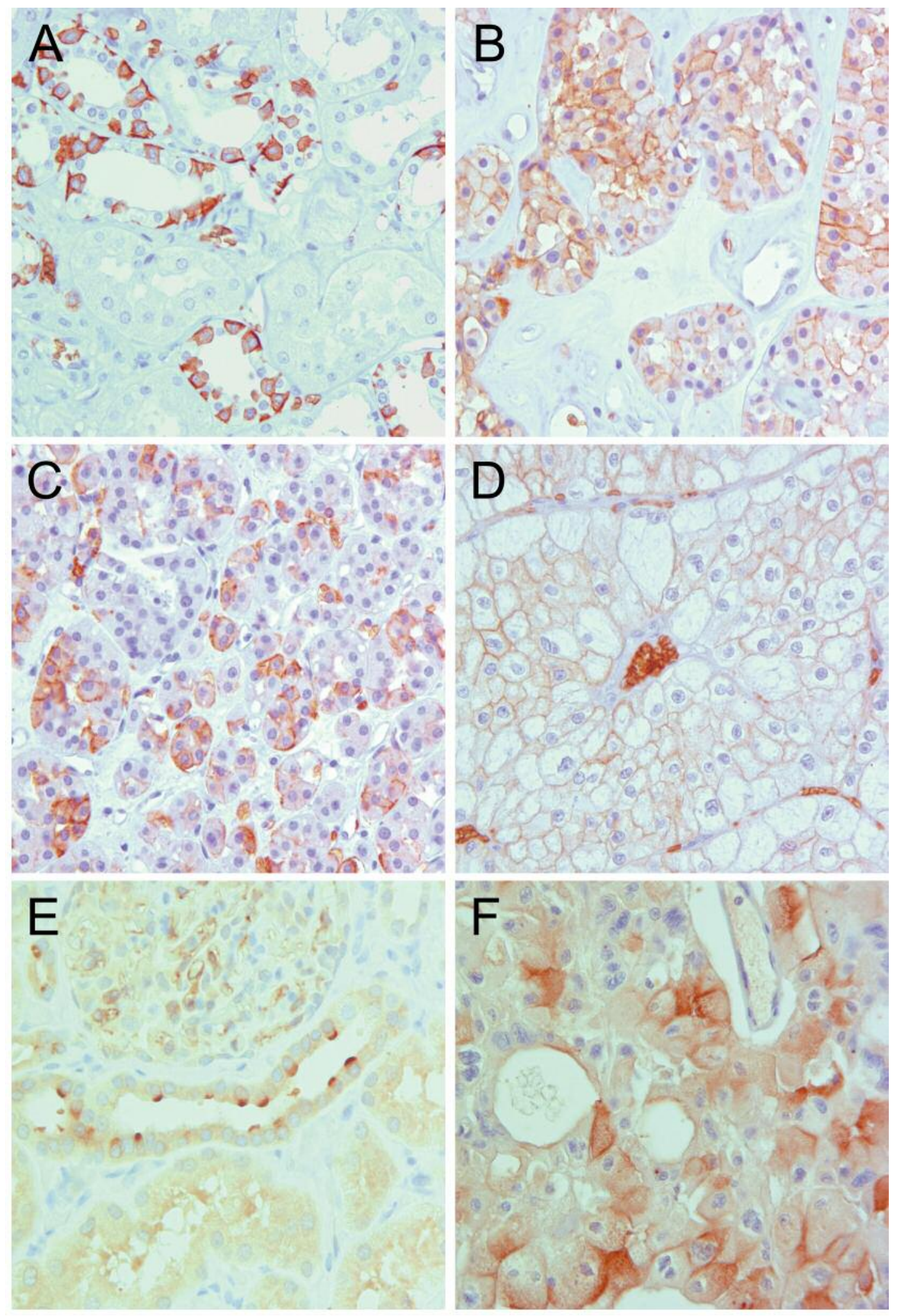

Figure 2. Expression of markers of intercalated cells in normal kidney and tumor tissues. A: Basolateral expression of solute carrier family 4 member 1 (SLC4A1) in connecting tubules of normal kidney. B and C: Similar expression pattern of SLC4A1 in renal oncocytoma. D: Membranous staining with SLC4A1 in a chromophobe renal cell carcinoma. E: Apical expression solute carrier family 26 member 4 (SLC26A4) in connecting tubules of normal kidney. F: Cytoplasmic and membranous staining with SLC26A4 in a chromophobe renal cell carcinoma. Scale bar: $25 \mu \mathrm{m}$. 
reaction with the $\alpha$-IC cell marker SLC4A1 was seen in $60 \%$ of ROs at a lower frequency than published in a small series of 10 tumors earlier (5). However, we also detected expression of SCL4A 1 in $11 \%$ of chRCCs. The $\beta$-IC cell marker SLC26A4 was not expressed except in but one chRCC, excluding $\beta$-IC cells as being the origin of chRCC. All tumors including conventional and papillary RCCs were negative for PC marker AQP2.

FOXI1 is required for the transcription of genes encoding four subunits of proton pump, SLC4A1, SLC26A4, SLC4A9 and $A T P 6 V 1 B 1$, in distal renal tubules and inner ear (21). SLC4A1 and SLC26A4 play a crucial role in the specification of $\beta$ - and $\alpha$-IC cells, respectively (21). In an experimental setting, mice lacking the Foxil gene did not develop IC cells expressing either Slc4al nor Slc26a4 (22). Interestingly, specific endolymphatic forkhead-related (FORE) cells in the inner ear also disappeared, suggesting that IC and FORE cells undergo a similar genetic program for their fate specification (23). During kidney development, ureteric bud cells expressing genes of the NOTCH signaling pathway differentiate into AQP2-positive PC cells. Cells turning off NOTCH signaling develop into proto-IC cells expressing FOXI1, which controls the transition of proto-IC cells into $\alpha$ - and $\beta$-IC cells or non$\alpha$-non- $\beta$-IC cells (11). In normal kidney, each cell type can be identified by the presence of specific markers.

Most tumors, especially the benign ones, retain the markers of their cellular origin. It is now accepted that $\beta$-IC cells are less differentiated, whereas $\alpha$-IC cells represent the more differentiated form of IC-cells (10). Taking into account the biological behavior of chRCC and RO, the former being malignant and the latter a more differentiated benign tumor, their origin from the less-differentiated $\beta$-IC cells and terminally differentiated $\alpha$-IC cells would be expected. However, our study showed that there are no such phenotypic correlations between RO and chRCC and $\alpha$ - and $\beta$-IC cells, respectively. One can speculate that both RO and chRCC develop from proto-IC cells expressing FOXI1, but in our study chRCC was not found to express FOXI1. Thus, the cellular origin of $\mathrm{RO}$ and chRCC remains unclear.

In conclusion, we cannot confirm the cellular origin of chRCC and RO as proposed by Stoerkel et al. $(5,6)$. However, we found the expression of FOXI1 transcription factor in $96 \%$ of ROs, but in only $3 \%$ of chRCCs. None of the other types of renal cell tumor expressed FOXI1. Therefore, we suggest that due to its high sensitivity and specificity, FOXI1 can be used as a marker for confirming the diagnosis of RO and distinguishing RO from chRCC and other renal cell tumors with eosinophilic cytoplasm.

\section{Conflicts of Interest}

The Authors have no conflicts of interest to declare in regard to this study.

\section{Authors' Contributions}

GK designed the research study, constructed the TMA and wrote the article; AM, CAH and PC performed the immunohistochemistry and analyzed the data, AS reviewed the article.

\section{Acknowledgements}

This work was supported by a grant of the Medical Faculty, University of Pecs, Hungary (PTE-AOK-KA-2018/16). The Authors would like to thank Ms Barbara Kanyo for her excellent technical assistance.

\section{References}

1 Davis CJ, Sesterhenn IA, Mostofi FK and Ho CK: Renal oncocytoma. Clinicopathological study of 166 patients. J Urogenital Pathol 1: 41-52, 1991.

2 Crotty TB, Farrow GM and Lieber MM: Chromophobe cell renal carcinoma: clinicopathological feature of 50 cases. J Urol 154: 964-967, 1995. PMID 7637102.

3 Mai KT, Dhamanaskar P, Belanger E and Stinson WA: Hybrid chromophobe renal cell neoplasm. Pathol Res Practice 201: 385389, 2005. PMID: 16047948. DOI: 10.1016/j.prp.2005.03.008

4 Pavlovich CP, Walther MM, Eyler RA, Hewitt SMm, Zbar B, Linehan WM and Merino MJ: Renal tumors in the Birt-HoggDubé syndrome. Am J Surg Pathol 26: 1542-1552, 2002. PMID: 12459621.

5 Störkel S, Pannen B, Thoenes W, Steart PV, Wagner S and Drenkhahn D: Intercalated cells as a probable source for the development of renal oncocytoma. Virchows Arch 56: 185-189, 1988. PMID: 2464871.

6 Störkel S, Steart PV, Drenckhahn D and Thoenes W: The human chromophobe cell renal carcinoma: its probable relation to intercalated cells of the collecting duct. Virchows Arch 56: 237245, 1989. PMID: 2565618.

7 Lindgren D, Eriksson P, Krawczyk K, Nilsson H, Hansson J, Veerla S, Sjölund J, Höglund M, Johansson ME and Axelson H: Cell-type-specific gene programs of normal human nephron define kidney cancer subtypes. Cell Rep 20: 1476-1489, 2017. PMID: 28793269. DOI: 10.1016/j.celrep.2017.07.043

8 Davis CF, Ricketss CJ, Wang M, Yang L, Cherniack AD, Shen H, Buhay C, Kang HG, Kim SC, Fahey CC, Hacker KE, Ghanot G, Gordenin DA, Chu A, Gunaratne PH, Biehl M, Seth S, Kaipparettu BA, Bristow CA, Donehower LA, Wallen EM, Smith AB, Tickoo SK, Tamboli P, Reuter V, Schmidt LS, Hsieh JJ, Choueiri TK, Hakimi AA; The Cancer Genome Atlas Research Network: The somatic genomic landscape of chromophobe renal cell carcinoma. Cancer Cell 26: 319-330, 2014. PMID: 25155756. DOI: 10.1016/j.ccr.2014.07.014

9 Rohan S, Tu JJ, Kao J, Mukherjee P, Campagne F, Zhou XK, Hyjek E, Alonso MA and Chen YT: Gene expression profiling separates renal cell carcinoma from oncocytoma and identifies vesicular transport and cell junction proteins as differentially expressed genes. Clin Cancer Res 12: 6937-6945, 2006. PMID: 17145811. DOI: $10.1158 / 1078-0432 . C C R-06-1268$

10 Al-Awqati Q: Cell biology of the intercalated cell in the kidney. FEBS Lett 587: 1911-1914, 2013. PMID: 23684635. DOI: 10.1016/j.febslet.2013.05.007 
11 Al-Awqati Q: 2007 Homer W. Smith Award: Control of terminal differentiation in epithelia. J Am Soc Nephrol 19: 443-449 2008. PMID: 18199795. DOI: 10.1681/ASN.2007111195

12 Treppiccione F, Soukaseum C, Iervolino A, Petrillo F, Zacchia M, Schutz G, Eladari D, Capasso G and Hadchouel J: A fatemapping approach reveals the composite origin of the connecting tubule and alerts on 'single-cell'-specific KO model of distal nephron. Am J Physiol Renal Physiol 311: F901-F906, 2016. PMID: 27582101. DOI: 10.1152/ajprenal.00286.2016

13 Speicher MR, Schoell B, du Manoir S, Schröck E, Ried T, Cremer T, Störkel S, Kovacs A and Kovacs G: Specific loss of chromosomes 1, 2, 6, 10,13, 17 and 21 in chromophobe renal cell carcinomas revealed by comparative genomic hybridisation. Am J Pathol 145: 356-364, 1994. PMID: 7519827.

14 Nagy A, Buzogany I and Kovacs G: Microsatellite allelotyping differentiates chromophobe renal cell carcinomas from renal oncocytomas and identifies new genetic changes. Histopathology 44: 542-546, 2004. PMID: 15186268. DOI: 10.1111/j.13652559.2004.01884.x

15 Bugert P and Kovacs G: Molecular differential diagnosis of renal cell carcinomas by microsatellite analysis. Am J Pathol 149: 2081-2088, 1996. PMID: 8952540.

16 Reuter VE, Argani P, Zhou M, Delahunt B; Members of the ISUP Immunohistochemistry in Diagnostic Urologic Pathology Group: Best Practice Recommendations in the Application of Immunohistochemistry in Kidney Tumors. Report from the International Society of Urologic Pathology Consensus Conference. Am J Surg Pathol 38: e35-e49, 2014. PMID: 25025368. DOI: 10.1097/PAS.0000000000000258

17 Ng KL, Rajandram R, Morais C, Yap NY, Samaratunga H, Gobe GC and Wood ST: Differentiation of oncocytoma from chromophobe renal cell carcinoma (RCC): Can novel molecular biomarkers help solve an old problem? J Clin Path 67: 97-104, 2014. PMID: 24170213. DOI: 10.1136/jclinpath-2013-201895

18 Williamson SR, Gadde R, Trpkov K, Hirsch MS, Srigley JR, Reuter VE, Cheng L, Kunju LP, Barod R, Rogers CG, Delahunt B, Hes O, Eble JN, Zhou M, McKenney JK, Matignoni G, Fleming S, Grognon D, Moch H and Gupta NS: Diagnostic criteria for oncocytic neoplasms: A survey of urologic pathologists. Hum Pathol 63: 149-156, 2017. PMID: 28315424. DOI: 10.1016/j.humpath.2017.03.004
19 Yusenko V M and Kovacs G: Identifying CD82 (KAI1) as a marker for human chromophobe renal cell carcinoma. Histopathology 55: 687-695, 2009. PMID: 20002769. DOI: 10.1111/j.1365-2559.2009.03449.x

20 Kovacs G, Akhtar M, Beckwith BJ, Bugert P, Cooper CS, Delahunt B, Eble JN, Fleming S, Ljungberg B, Medeiros LJ, Moch H, Reuter VE, Ritz E, Roos G, Schmidt D, Srigley JR, Störkel S, van den Berg E and Zbar B: The Heidelberg classification of renal cell tumours. J Pathol 183: 131-133, 1997. PMID: 9390023. DOI: 10.1002/(SICI) 1096-9896(199710)183:2 $<131:$ :AID-PATH931>3.0.CO;2-G

21 Vidarsson H, Westergren R, Heglind M, Blomqvist SR, Breton $\mathrm{S}$ and Enerback $\mathrm{S}$ : The forkhead transcription factor FOXI1 is a master regulator of vacuolar H-ATP-ase proton pump subunits in the inner ear, kidney and epididymis. PLos ONE 4: e4471, 2009. PMID: 19214237. DOI: 10.1371/journal.pone.0004471

22 Blomqvist SR, Vidarsson H, Fitzgerald S, Johansson BR, Ollerstam A, Brown R, Persson AE, Bergström GG and Enerback S: Distal renal tubular acidosis in mice that lack the forkhead transcription factor Foxil. J Clin Invest 113: 15601570, 2004. PMID: 15173882. DOI: 10.1172/JCI20665

23 Hulander M, Kiernan AE, Blomqvist SR, Carlsson P, Samuelsson EJ, Johansson BR, Steeel KP and Enerback S: Lack of pendrin expression leads to deafness and expansion of the endolymphatic compartment in inner ears of Foxil-null mutant mice. Development 130: 2013-2025, 2003. PMID: 12642503.
Received April 30, 2019

Revised May 21, 2019

Accepted May 23, 2019 